\title{
Nigella sativa protects against formaldehyde- induced neurotoxicity in the rat frontal cortex
}

\author{
Abd El-Rahman El-Shahat Mohamad ${ }^{1,4}$, Tarek Mohamed Essa ${ }^{2,4}$, Hesham Saad Ata ${ }^{3,5}$ \\ ${ }^{1}$ Department of Anatomy and Embryology, Faculty of Medicine, Cairo University, Cairo, Egypt \\ ${ }^{2}$ Department of Anatomy and Embryology, Faculty of Medicine, Alexandria University, Alexandria, Egypt \\ ${ }^{3}$ Department of Pathology, Faculty of Medicine, Assiut University, Assiut, Egypt \\ ${ }^{4}$ Department of Anatomy and Embryology, Faculty of Medicine, Qassim University, Qassim, Saudi Arabia \\ 'Department of Pathology, College of Medicine, Qassim University, Qassim, Saudi Arabia
}

\begin{abstract}
Objectives: Nigella sativa (NS) is well known for its strong antioxidant properties. The aim of this study was to investigate the potential protective effect of NS, as a potent antioxidant and free radical scavenger, on the rat frontal cortex following formaldehyde (FA)-induced neuronal injury and oxidative stress.

Methods: Forty albino rats were divided into four groups ( $n=10$, each): control group received $1 \mathrm{ml}$ distilled water, NS treated group crushed seeds of NS at a single daily dose of $180 \mathrm{mg} / \mathrm{kg} / \mathrm{bw}$ orally for two weeks, FA-treated group $10 \mathrm{mg} / \mathrm{kg} / \mathrm{bw}$ FA i.p. daily for two weeks, and FA and NS treated group received $10 \mathrm{mg} / \mathrm{kg} / \mathrm{bw}$ FA i.p. followed by a single dose of NS (180 $\mathrm{mg} / \mathrm{kg} / \mathrm{bw}$ ) orally for 2 weeks. The animals then were sacrificed and the frontal lobes were excised. Frontal cortex was stained with hematoxylen-eosin and caspase-3 immunohistochemistry to identify cell morphology and apoptosis. Lipid peroxide, nitric oxide, superoxide dismutase and glutathione levels were measured.

Results: Histological examination revealed severe neurodegenerative changes in frontal cortex neurons in the FA-treated group as observed with hematoxylen-eosin and caspase-3 immunohistochemistry. However, these changes were partly prevented in the FA and NS-treated group. Apoptotic cell index in the frontal cortex decreased significantly in FA and NS treated rats compared to FA-treated rats. In the FA-treated group, lipid peroxide levels increased, while nitric oxide and glutathione levels decreased significantly compared with controls. In the FA + NS treated group, nitric oxide, glutathione and superoxide dismutase levels increased and lipid peroxide level decreased significantly when compared with the FA-treated group.
\end{abstract}

Conclusion: NS administration protects frontal cortex neurons against oxidative damage induced by FA.

Keywords: cerebral cortex; formaldehyde; neuronal injury; Nigella sativa; oxidative stress; rat

Anatomy 2015;9(3):117-127 @2015 Turkish Society of Anatomy and Clinical Anatomy (TSACA)

\section{Introduction}

Formaldehyde (FA) is a compound commonly used in industry and medicine that can react with different macromolecules such as proteins, nucleic acids and low molecular weight substances as amino acids. ${ }^{[1,2]}$ In particular, anatomists and medical students are exposed to FA gas during cadaver dissections. ${ }^{[3,4]}$ Humans are exposed to FA from direct environmental sources like paint, plywood, cosmetics, cigarette smoke, photochemical smog and even various fruits as well as from the metabolism of xenobiotics ${ }^{[5,6]} \mathrm{FA}$ is accepted as toxic over certain doses and its at high room temperatures its harmful effects increase due to volatility. ${ }^{[7-10]}$ Physiological FA forms by the metabolism of L-methionine, histamine or methylamine in the body, and contribute to biological methylation by folic acid. ${ }^{[11]}$

Acute exposure to FA causes central nervous system symptoms such as headache, malaise, insomnia, anorexia 
and dizziness. ${ }^{[12]}$ Some studies have linked chronic FA exposure in humans to neurodegenerative diseases. ${ }^{[13]}$ Inhaled FA has also been shown to cause behavioral and memory disorders in rats and has been defined as probably cytotoxic. ${ }^{[14-16]}$ Long-term exposure to FA from 14 to 30 years may cause irreversible neurotoxicity and was suggested to be related to astrocytoma in the brain. ${ }^{[17]}$

Because neurons have an elevated metabolic rate and high content of oxidizable substrates, neural tissues are highly sensitive to free radical attacks. ${ }^{[18]} \mathrm{FA}$ causes oxidative stress by inducing the generation of reactive oxygen species (ROS) and reducing the antioxidant cell defense systems ${ }^{[19]}$ ROS, including singlet oxygen, hydrogen peroxide, superoxide anion and hydroxyl radical, can be produced as a result of cell aerobic metabolism and inflammation by endogenous sources, or by exposure to a variety of chemical materials like FA or other physical agents. ROS are important mediators of cellular injury and play a putative role in oxidative stress, contributing to a variety of diseases or cases of toxicity such as methanol intoxication as a metabolite of $\mathrm{FA}^{\left[{ }^{[20,21]}\right.}$ Cell defense mechanisms, which including superoxide dismutase (SOD), and glutathione (GSH) can regulate ROSinitiated oxidative stress. ${ }^{[2]}$

The harmful consequences of membrane peroxidation caused by ROS have enforced investigations on the efficacy and mechanisms of action of biologically relevant antioxidants, particularly naturally occurring ones, including those used as foods and beverages like a black seed from the Ranunculaceae family, Nigella sativa (NS). ${ }^{[19]}$ NS contains more than $30 \%$ fixed oil and $0.4-0.45 \%$ $\mathrm{wt} / \mathrm{wt}$ of volatile oil with thymoquinone and monoterpenes. ${ }^{[23]}$ Thymoquinone is the most pharmacologically active ingredient found abundantly in NS black seeds. ${ }^{[24]}$ It is reported that the volatile components of NS such as thymoquinone decreases lipid peroxidation through suppression of reactive oxygen and nitrogen species formation and increases antioxidant defense system activity. ${ }^{[25,26]}$

NS extracts have bronchodilatator, antibacterial, hypotensive, antidiabetic, gastro-protective, hepatoprotective, antihistaminic, anti-oxidative and neuroprotective effects. ${ }^{[27-30]}$

The present study was carried out to investigate the antioxidant and protective effects of NS against oxidative stress and neuronal damage induced by FA administration on the frontal lobe of the rat brain, using histological, immunohistochemical and biochemical methods.

\section{Materials and Methods}

\section{Animals}

Forty healthy male albino rats weighing 250-300 g were utilized in this study. The rats were housed in the animal facility at Faculty of Medicine, Qassim University, Qassim, Saudi Arabia. The experimental protocol was approved by the Ethics Committee of Faculty of Medicine of Alexandria University (approval number: 0302669). The rats were maintained in individual stainless steel cages where temperature $\left(23 \pm 1{ }^{\circ} \mathrm{C}\right)$, relative humidity $(50 \pm 10 \%)$ and illumination (lights on at $7 \mathrm{AM}$ and off at 9 PM: $14 \mathrm{~h} \mathrm{light/10} \mathrm{h} \mathrm{dark} \mathrm{cycle)} \mathrm{were} \mathrm{auto-}$ matically controlled. Rats had access to a standard rodent laboratory diet and drinking water.

\section{Plant material}

NS seeds were purchased from a local herb store in Qassim, Saudi Arabia. The seeds of NS were crushed, suspended in distilled water and given orally by appropriate gastric tube as daily dose of $180 \mathrm{mg} / \mathrm{kg} / \mathrm{bw}$. This dose corresponds to human therapeutic dose of two grams of NS/70 kg man/day. ${ }^{[3]}$

\section{Chemicals}

Thiobarbituric acid, butylated hydroxyl toludine, reduced glutathione, sodium sulfate, sodium nitrite, epinephrine, naphthy lethyene diaminedihydrochloride, sulphanilamide and 5',5'- dithiobis-2-nitro-benzoic acid were purchased from Sigma (St. Louis, MO, USA).

\section{Experimental design}

The rats were randomly divided into four groups. Each group contained 10 animals; control, FA-treated, NS treated and FA and NS treated. Control rats were given $1 \mathrm{ml} / \mathrm{kg} / \mathrm{bw}$ distilled water orally daily in the morning for 2 weeks. FA-treated group received intraperitoneal (IP) injection of $10 \mathrm{mg} / \mathrm{kg} / \mathrm{bw}$ FA daily in the morning for 2 weeks. ${ }^{[2,33]}$ The rats treated with NS were given a single dose of NS $180 \mathrm{mg} / \mathrm{kg} / \mathrm{bw}$ daily orally in the morning for 2 weeks. FA and NS treated group were given IP injection of $10 \mathrm{mg} / \mathrm{kg} / \mathrm{bw}$ FA followed by NS (in a dose of $180 \mathrm{mg} / \mathrm{kg} / \mathrm{bw}$ ) once a day orally for 2 weeks in the morning. Every rat was weighed daily, and the mean weight of each group was calculated at the start and end of the experiment. The animals of all groups were anaesthetized using diethyl ether and then sacrificed. Frontal lobes were excised and divided into two parts. One part was used for histological and immunohistochemical examination and the other for biochemical investigations. 


\section{Histological and immunohistochemical analysis}

The frontal lobes of each animal were fixed in $10 \%$ neutral buffered formaldehyde. Two specimens from each lobe were rinsed with $70 \%$ ethanol, dehydrated through graded ethanol series, then cleared in xylene before being embedded in paraffin. Coronal sections at $5 \mu \mathrm{m}$ thickness were cut, stained with heamatoxylin and eosin, and then examined under the light microscope. Five non-overlapping sections from each specimen were studied.

Endogenous peroxidase activity was blocked by incubating the tissue sections with $3 \% \mathrm{H}_{2} \mathrm{O}_{2}$ for $30 \mathrm{~min}$, followed by $10 \%$ normal goat serum for $1 \mathrm{~h}$ at room temperature (RT). Then, rabbit polyclonal anticaspase-3 antibody (1:50; NeoMarkers, Fremont, CA) was applied for $30 \mathrm{~min}$ at RT, followed by secondary antibody (Econo Tek biotinylated anti-polyvalent antibody ü, ScyTek laboratories, USA) for $30 \mathrm{~min}$ at RT. Sections were then incubated with ABC (Dako labeled streptavidin biotin - LSAB 2) Kit for $20 \mathrm{~min}$. Four drops of diaminobenzedine (DAB) substrate was used as chromogen. Sections were counterstained with hematoxylin, dehydrated through a graded ethanol series, mounted in DAKO paramount and cover-slipped. As negative control, primary antibody (anti-caspase 3 antibody) was replaced with PBS.

The total number of neurons and apoptotic neurons (strong caspase-3 immunoreactive) were counted in five non-overlapping fields in five serial sections under light microscope with the use of a standardized ocular grid (X 400). The apoptotic cell index (ACI = apoptotic cells/total cells) was calculated and used as an indicator of the degree of apoptosis. ${ }^{[34]}$ Results were presented as mean $\pm \mathrm{SE}$.

\section{Biochemical analysis}

The brain tissue was homogenized in ice-cold $100 \mathrm{mM}$ phosphate buffer ( $\mathrm{pH}$ 7.4) using potter-Elvehjem homogenizer fitted with a Teflon plunger. Homogenates were centrifuged at $11,000 \mathrm{~g}$ for $20 \mathrm{~min}$, and the resulting supernatants were divided into aliquots and stored at -70 ${ }^{\circ} \mathrm{C}$. Lipid peroxide (LPO) levels were measured as thiobarbituric acid reactivities. ${ }^{[35]}$ Nitric oxide (NO) level was determined as total nitrite after deproteinization with $\mathrm{ZnSO}_{4}$ (30\%), and reduction by cadmium in presence of $\mathrm{NH}_{4} \mathrm{Cl}$ and sodium borate. Color developed by reaction with Griessreagen was recorded at $550 \mathrm{~nm}$ against reagent blank using sodium nitrite $10-100 \mathrm{uM}$ as standard. ${ }^{[36]}$ SOD activity was determined according to its ability to inhibit auto-oxidation of epinephrine at alkaline medium. ${ }^{[37]} \mathrm{GSH}$ concentration was determined chemically as described by Dutta et al. ${ }^{[38]}$

\section{Statistical analysis}

The results were expressed as mean \pm standard error (SE). Differences between groups were assessed by oneway analysis of variance, ANOVA, using the Prism version 5 software packages for Windows. Measurements were considered statistically significant when probability was less than $0.05(\mathrm{p}<0.05)$.

\section{Results}

The mean weights of the rats of different groups are shown in Figure 1. A significant increase was found in the weight of the rats in the control, NS treated, and FA and NS treated groups at the end of the experiment compared with their weight at the beginning of the experiment. However, in the FA-treated group, the weight of the rats significantly decreased at the end of the experiment compared with their weight at the beginning of the experiment.

Examination of the heamatoxylin and eosin stained sections of the frontal cortex in the control group showed normal histological features such as normal cellularity, normal appearance of neurons with their large nuclei and dispersed chromatin. The cytoplasm appeared basophilic (Figure 2). In the NS treated group, the sections of the frontal cortex were similar to the control group (Figure 3). In the FA-treated group, the most consistent findings were severe neurodegenerative changes including irregular outline of the neuronal perikarya, shrunken and deeply acidophilic cytoplasm (red neurons), and extensively dark pyknotic nuclei (Figure 4). There was focal perivascular inflammatory

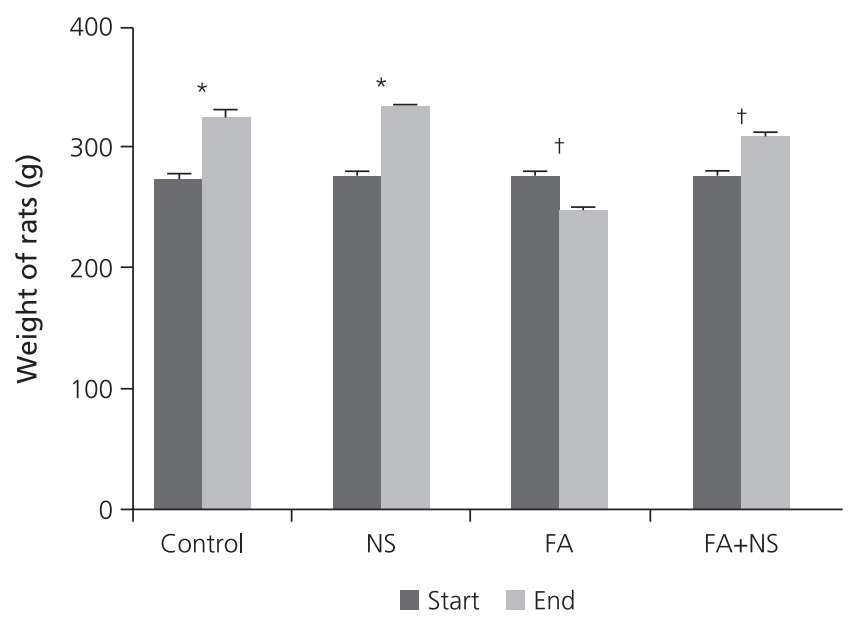

Figure 1. Weight of rats (mean $\pm \mathrm{SE}$ ) in control, NS-treated, FA-treated, and FA+NS treated groups at the start and the end of the experiment. ${ }^{*} \mathrm{p}<0.001 ;+\mathrm{p}<0.01$ 

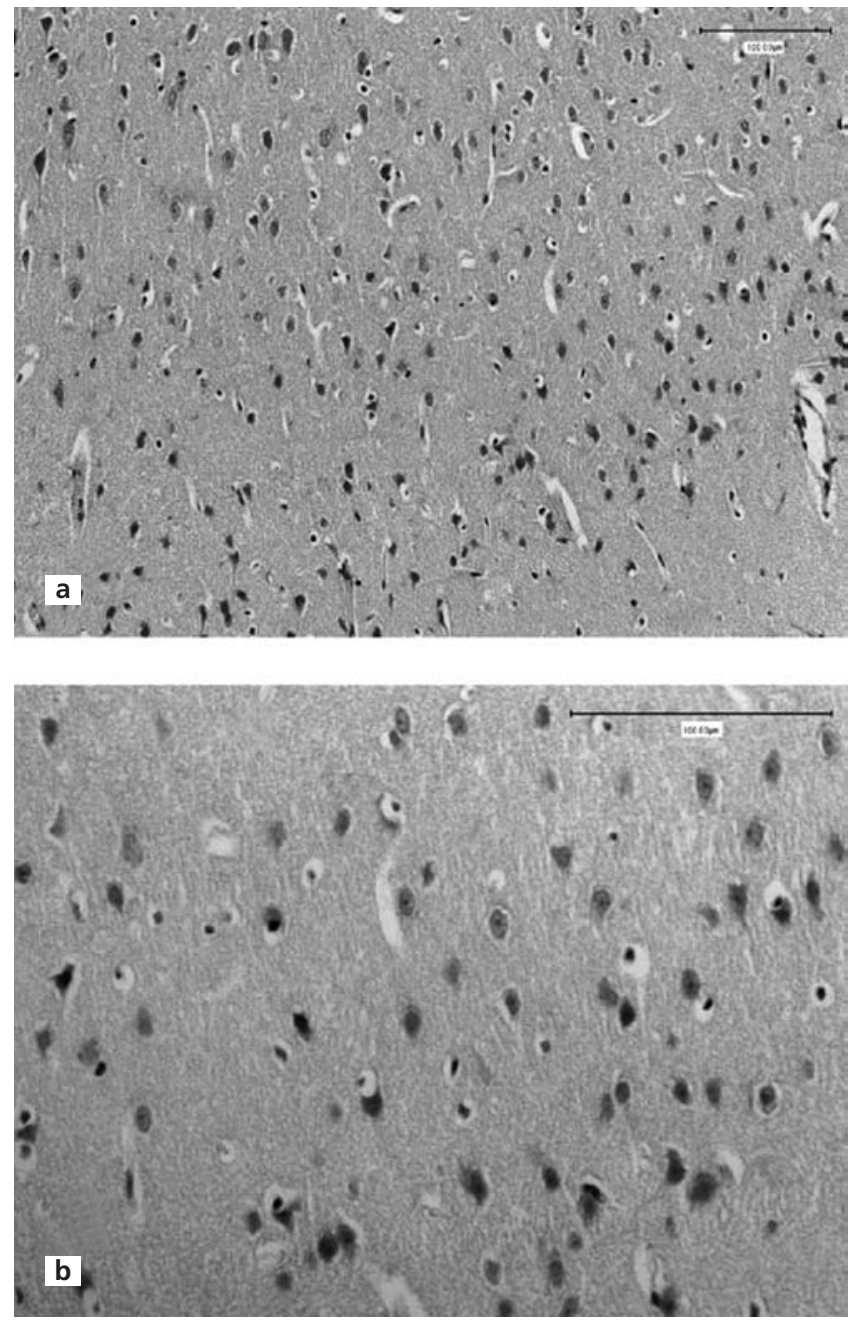

Figure 2. (a, b) Frontal cortex of the control group with normal histological features - neurons with large nuclei and dispersed chromatin. Scale bar $=1 \mathrm{~mm}$.

reaction infiltrating the cerebral cortex (Figure 5). In the NS and FA-treated group, the intensity of neuronal changes was less than in the FA-treated group; the darkly stained nuclei and the distorted nerve cells were reduced markedly. The severity of degenerative changes in the cytoplasm of the cells was less than that of the FAtreated group (Figure 6).

In immunohistochemical examination, no caspase-3 immunoreactivity was observed in the nuclei of the neurons in control rats (Figure 7). Apoptotic neurons were stained positively with caspase- 3 in FA-treated rats. Caspase- 3 immunoreactivity increased in degenerating neurons of the frontal cortex tissues following FA exposure (Figure 8). In the FA and NS treated group, there was a marked reduction in the apoptotic neurons indicat-
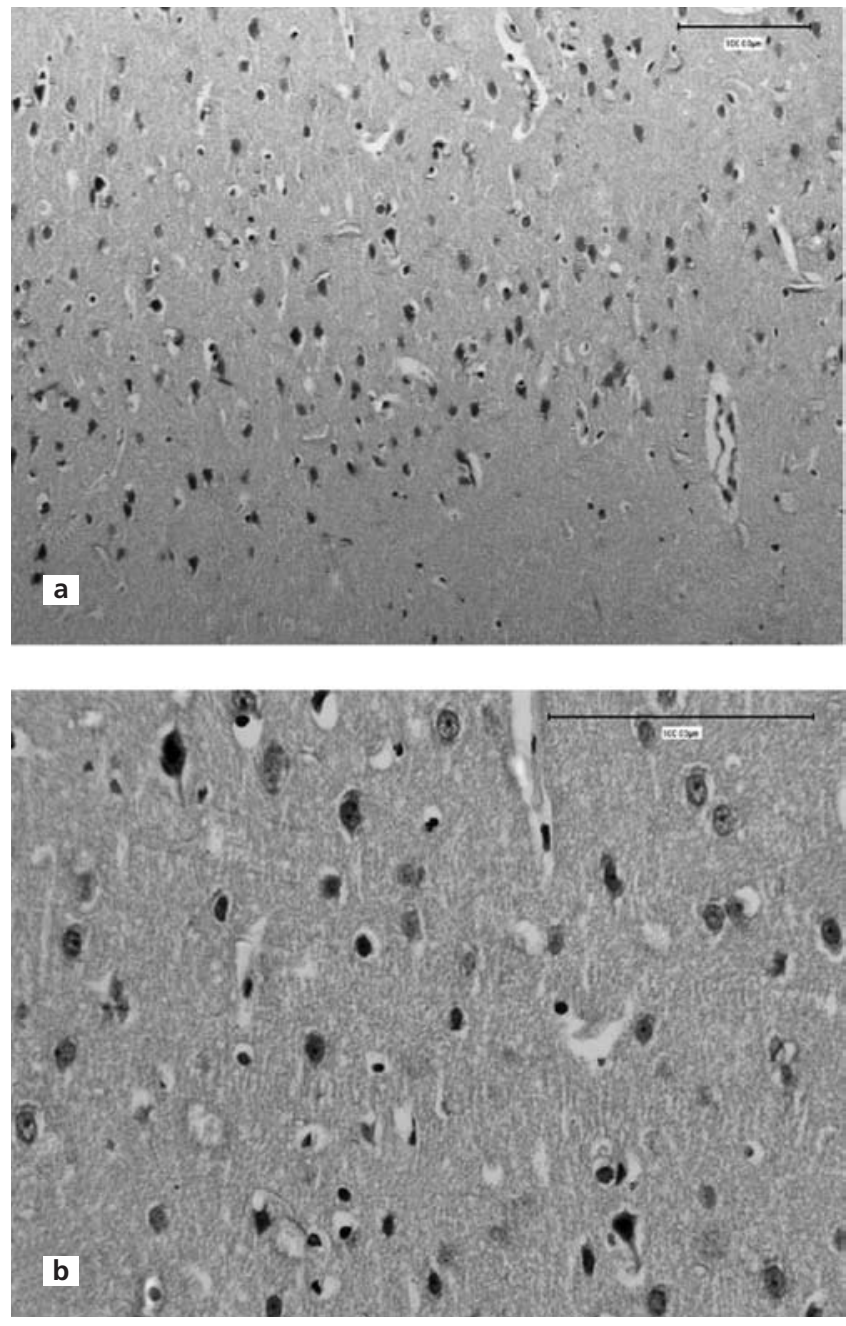

Figure 3. (a, b) Frontal cortex of NS-treated group showing normal histological features with normal cellularity, normal appearance of neurons with their large nuclei and dispersed chromatin. Scale bar $=1 \mathrm{~mm}$.

ed by marked decrease of caspase-3 immunoreactivity (Figure 9).

Apoptotic cell index increased significantly in FAtreated rats compared to control, while it decreased significantly in FA and NS treated group in frontal cortex tissues compared to FA-treated rats. The number of apoptotic neurons and apoptotic cell index in the frontal cortex of all studied groups are shown in Table 1.

Mean levels of LPO, NO, GSH and SOD in the brain tissues were shown in Figure 10. LPO level in the FAtreated group increased significantly in comparison with control group. However, LPO in the FA+NS treated group showed a significant reduction compared to the FAtreated group. NO and GSH levels of the FA-treated group decreased significantly in comparison to the con- 

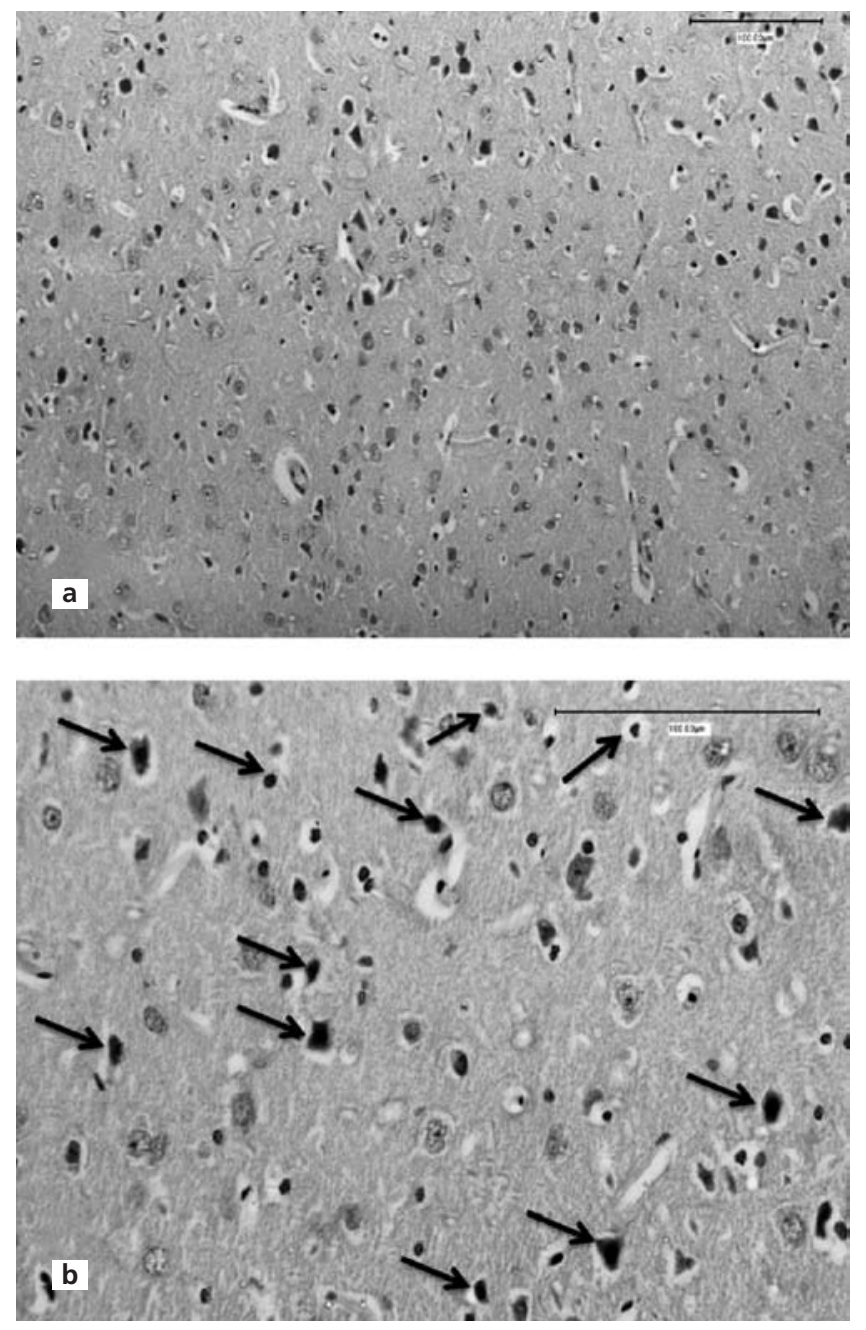

Figure 4. (a, b) Photomicrograph of a coronal section in the rat frontal cortex of FA-treated group showing marked degenerative changes including irregular outline of neuronal perikarya with shrunken deeply acidophilic cytoplasm and extensively darkly stained pyknotic nuclei (arrows). Hematoxylin and eosin stain. Scale bar $=1 \mathrm{~mm}$.

trol. The levels of NO, GSH and SOD activities in brain tissues of FA + NS treated group showed a significant elevation compared to the FA-treated group.

\section{Discussion}

FA is a toxic substance classified as a carcinogen in humans by the Cancer Research Center. ${ }^{[39]}$ It causes production of oxygen radicals after entering the organism that leads to inflammation and apoptosis of most of the body cells. ${ }^{[40]}$

The present study was carried out to evaluate the histological changes in the frontal cortex of the rats and the oxidative damage caused by FA and the possible protective effect of NS. Neurocytoxicity mechanisms of FA
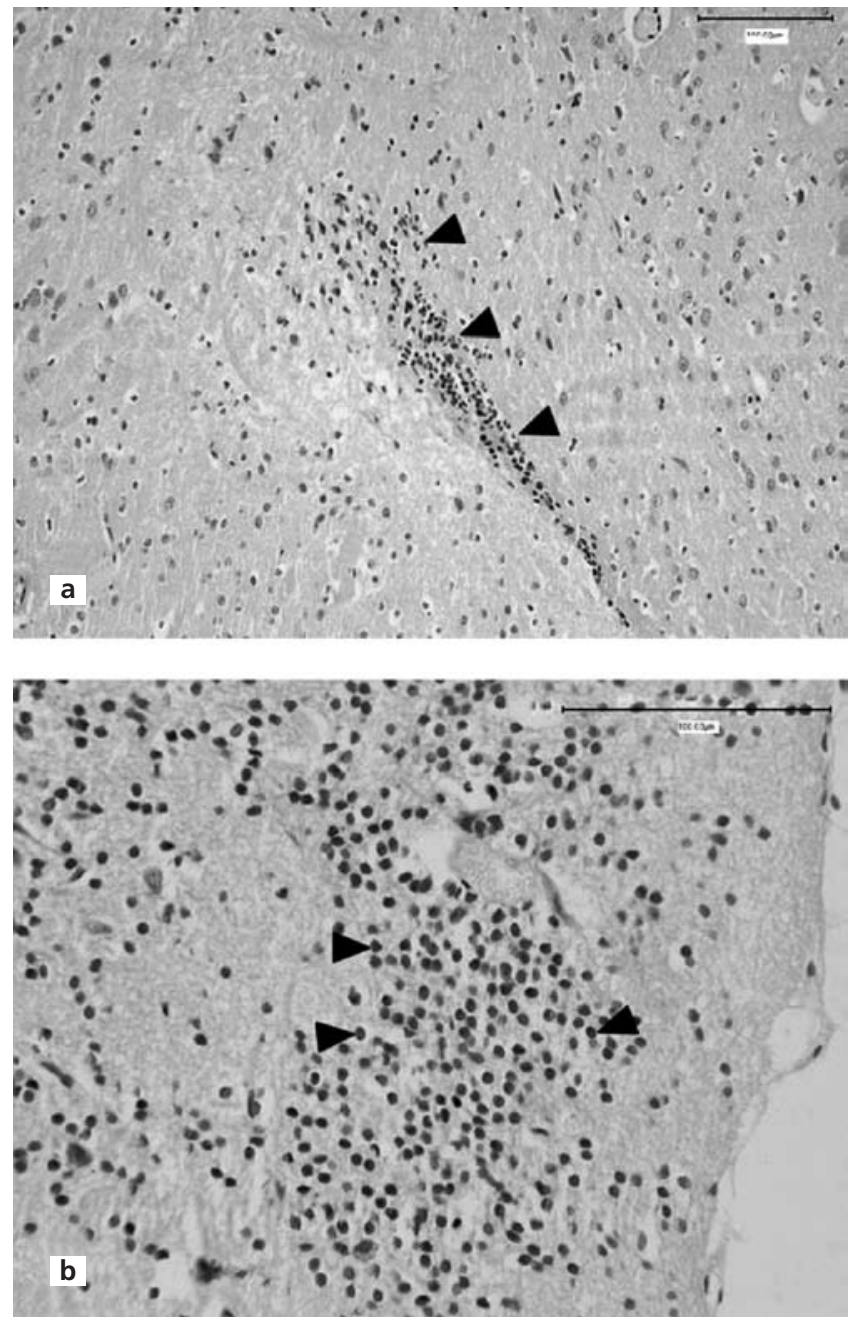

Figure 5. $(\mathbf{a}, \mathbf{b})$ Photomicrograph of a coronal section in the rat frontal cortex of FA-treated group showing focal perivascular inflammatory reaction with inflammatory cells infiltrating the parenchyma (arrowheads). Hematoxylin and eosin stain. Scale bar $=1 \mathrm{~mm}$.

have not been revealed understood; they are assumed to be mediated by increased ROS through the activation of free radical producing enzymes and the inhibition of free radical scavenger systems. ${ }^{[3]}$

Acute FA administration at low concentrations stimulates the central nervous system activity, but in contrast, depresses when applied in higher concentrations. ${ }^{[4]]} \mathrm{Lu}$ et al. ${ }^{[16]}$ and Kanter et al. ${ }^{[33]}$ found that rats that were systemically exposed to FA had several behavioral disorders. In agreement with these reports, the present study observed that there was significant decrease of the weight in the FA-treated rats. Solomons and Cochrane ${ }^{[12]}$ showed that FA causes anorexia, and this may explain the decrease in the weight of the rats treated with FA in our study. 

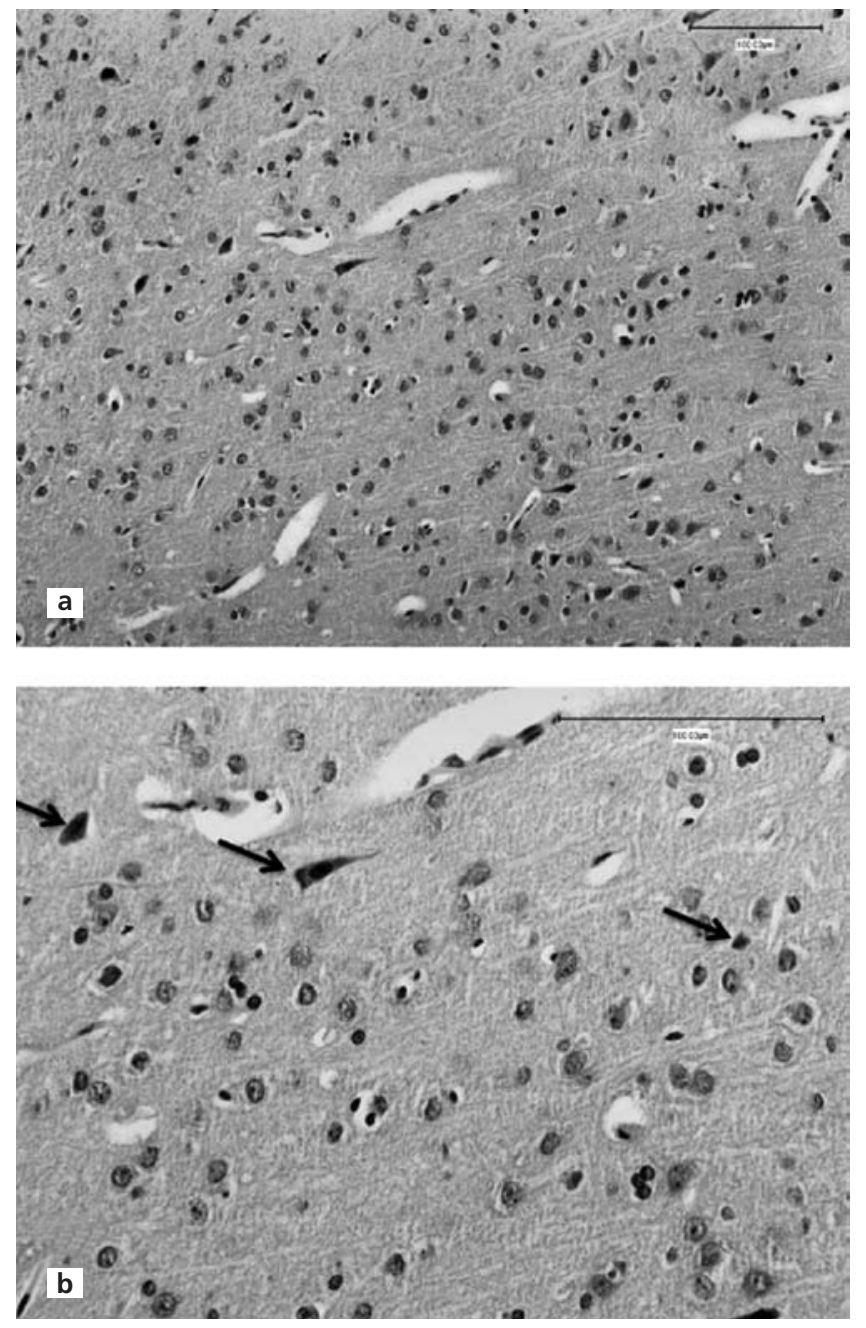

Figure 6. (a, b) Photomicrograph of a coronal section in the rat frontal cortex of FA and NS-treated group showing mild degenerative changes with few apoptotic cells (arrows). Cellularity is normal. There is no inflammatory reaction. Hematoxylin and eosin stain. Scale bar $=1 \mathrm{~mm}$.

The brain requires very high amounts of oxygen per unit weight and has a high content of easily peroxidizable unsaturated fatty acids, making it susceptible to free radical damage. With the toxic effect of FA or its derivatives, ROS attack membrane-associated polyunsaturated fatty acids that results in lipid peroxidation in the cell membrane resulting in impaired cellular function and necrosis. ${ }^{[42]}$ In the current study, FA caused severe neurodegenerative changes, shrunken and deeply acidophilic cytoplasm and extensively dark pyknotic nuclei in frontal cortex neurons. There was also a perivascular inflammatory reaction infiltrating the cerebral cortex parenchyma. The number of apoptotic neurons and the apoptotic cell index increased significantly in FA-treated rats compared to controls. This observation is in agreement with the
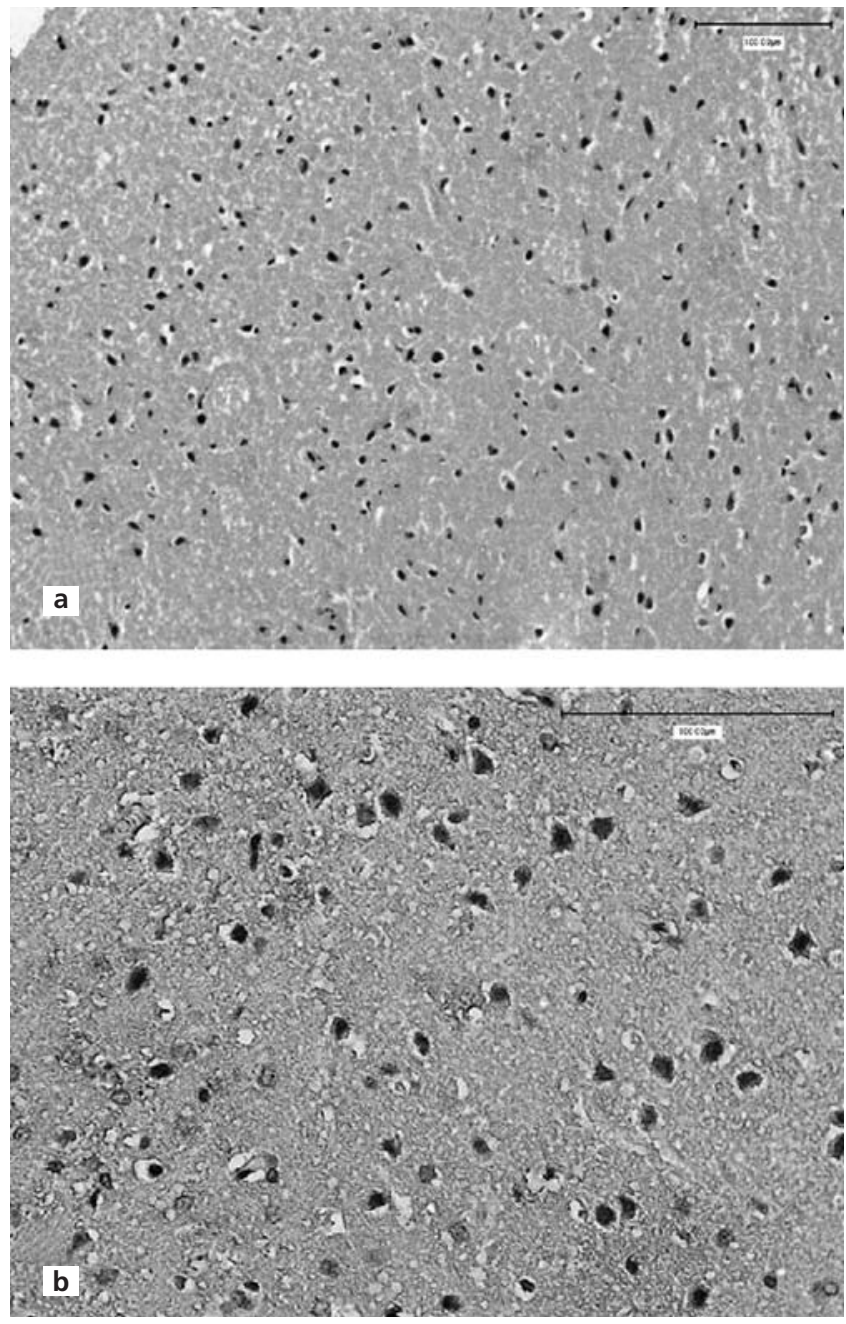

Figure 7. (a, b) Immunohistochemical staining with anti-caspase 3 in the rat frontal cortex of control group showing no immuno-reactivity. The nuclei are stained blue. Scale bar $=1 \mathrm{~mm}$.

finding of Zhang et al. ${ }^{[40]}$ and Kanter. ${ }^{[3]}$ Datta and Namasivayam $^{[42]}$ and Farooqui et al..$^{[43]}$ suggested that FA exposure in experimental animals has a negative impact on the antioxidant system; impaired antioxidant enzyme activity causes ROS-induced membrane lipid and protein oxidation leading to delayed apoptotic/necrotic cell death. $^{[40,42-44]}$

The current study revealed a significant increase in the levels of LPO in the brain tissue in FA-treated rats compared to the control group. Similar findings were observed in rats treated with lead acetate. ${ }^{[45,46]}$

$\mathrm{NO}$ is synthesized predominantly in the vascular endothelium. ${ }^{[4]}$ Endothelial nitric oxide synthase (eNOS) is required for the synthesis of NO from L-argi- 

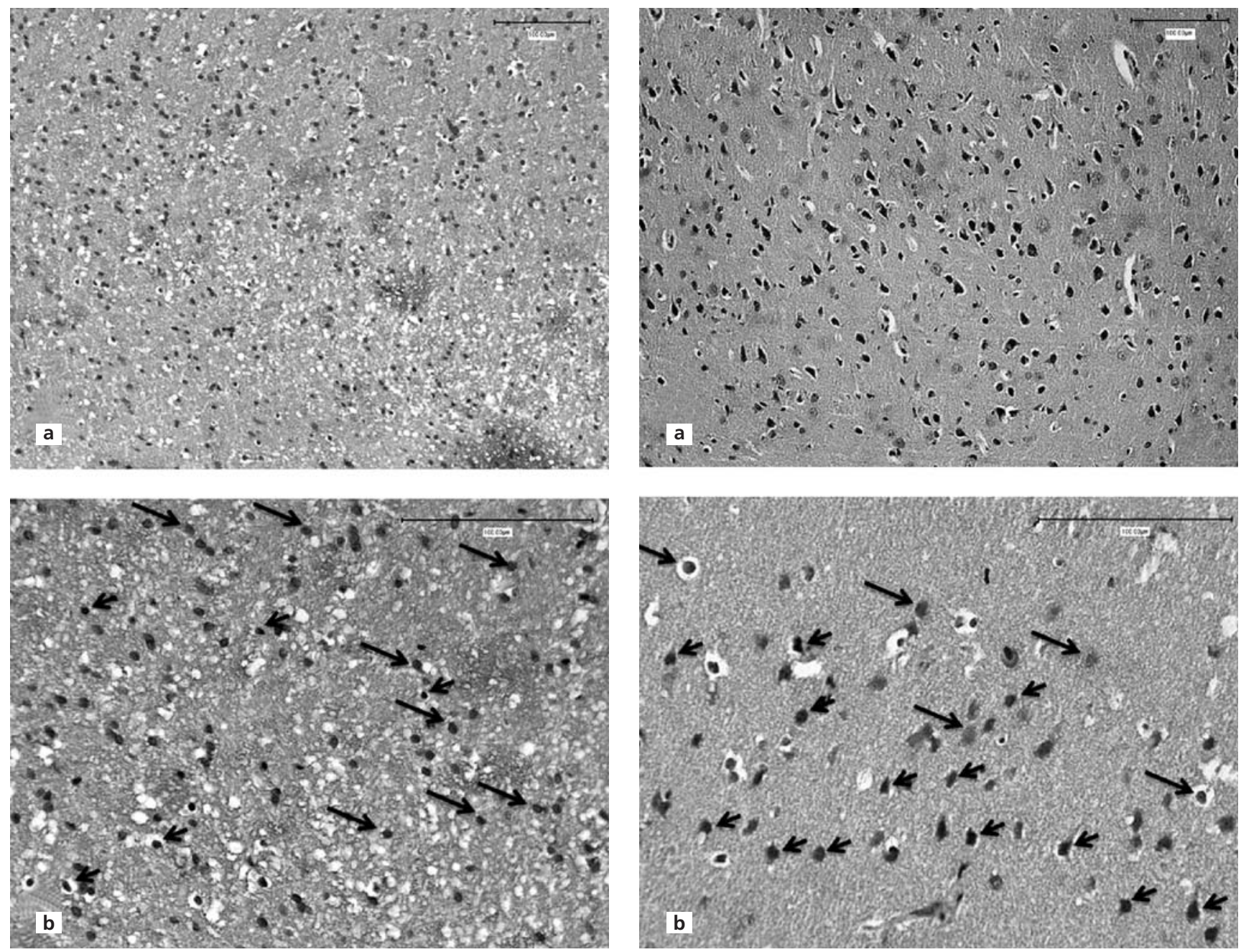

Figure 8. (a, b) Immunohistochemical staining with anti-caspase 3 antibody in the rat frontal cortex of FA-treated group showing dense and numerous positive staining in neurons indicating high apoptotic activity. The nuclei are stained brown (long arrows). Nuclei of normal neurons are indicated with short arrows. Scale bar $=1 \mathrm{~mm}$.

Figure 9. (a, b) Immunohistochemical staining with anti-caspase 3 in FA and NS- treated group showing decreased immunoreactivity indicating a decreased number of apoptotic bodies (long arrows) compared to FA- treated group. Short arrows: nuclei of normal neurons. Scale bar $=1 \mathrm{~mm}$.

nine. There are two other isoforms of NOS, namely, neuronal nitric oxide synthase (nNOS) and inducible nitric oxide synthase (iNOS). NO is small in size and lipophilic by nature, allowing it to diffuse rapidly through cell membranes to adjacent smooth muscle cells. Generation of ROS such as superoxide anions oxidizes membrane lipids, proteins, and nucleic acids. Superoxide anions reduce NO bioavailability by binding to the gaseous molecule and forming the free radical peroxy nitrite. In the present study, the levels of NO were significantly lower in the brain tissue of FA-treated rats than in controls. Similarly, Bannet et al. ${ }^{[4]}$ found significant reduction in the levels of $\mathrm{NO}$ in rats exposed to heavy metals in drinking water for 10 months which caused an increase in ROS.

Natural defense mechanisms, such as antioxidant enzymes widely distributed in the organism neutralize the deleterious effects of oxidative stress. SOD and GSH are two antioxidant substances widely distributed in the organism, so they are measured as a reference for the damage degree of tissue lipid peroxidation. ${ }^{[48,49]} \mathrm{GSH}$ helps in detoxification and excretion of toxic compounds. ${ }^{[50]} \mathrm{GSH}$ directly interacts ROS or is involved in enzymatic detoxification reactions for ROS as a co-factor. $^{[51]}$ In the current study, GSH levels significantly decreased in the brain tissue of FA-treated rats, com- 
pared to controls. Similar to our study, Saxena and Flora ${ }^{[52]}$ reported that a pronounced depletion of rat brain GSH contents were correlated with an increased uptake of toxic heavy metals.

NS is well known for its strong antioxidant properties. ${ }^{[53]}$ Pretreatment with thymoquinone, the main active constituents in NS, protects organs against oxidative damage induced by a variety of free radical generating agents. ${ }^{[5]}$ The free radical scavenging effects of thymoquinone, dithymoquinone, and thymol were tested against several ROS. ${ }^{[5]}$ Hosseinzadeh et al. ${ }^{[25]}$ and $\mathrm{Al}-$ Omar et al. ${ }^{[56]}$ reported that thymoquinone prevents membrane lipid peroxidation and protects rats against transient forebrain ischemia-induced damage in the rat hippocampus.

The present study investigated the effects of NS, as a potent antioxidant and free radical scavenger, on FAinduced neuronal injury and oxidative stress in the rat
Table 1

The number of apoptotic cells per $5 \mu \mathrm{m}$ thick coronal section and apoptotic cell index (mean=SE) in the frontal cortex tissue of control, NS treated, FA-treated and FA and NS treated groups.

\begin{tabular}{lcc}
\hline Group & $\begin{array}{c}\text { Number of } \\
\text { apoptotic cells }\end{array}$ & $\begin{array}{c}\text { Apoptotic } \\
\text { cell index }\end{array}$ \\
\hline Control & $9.04 \pm 0.27$ & $0.092 \pm 0.02$ \\
NS-treated & $9.78 \pm 0.31$ & $0.084 \pm 0.002$ \\
FA-treated & $69.92 \pm .23^{*}$ & $0.59 \pm 0.01^{*}$ \\
FA+NS treated & $16.42 \pm 0.50^{*},+$ & $0.14 \pm 0.003 \xi, \dagger$ \\
\hline
\end{tabular}

${ }^{*} \mathrm{p}<0.001$ for comparison of all the studied groups versus controls. ${ }^{\dagger} \mathrm{p}<0.001$ for comparison of FA-treated group versus FA and NS-treated group. $\S_{p}<0.05$ for comparison of all the studied groups versus controls.

frontal cortex. The histological and immunohistochemical results of this study show that NS has a protective effect against FA-induced neuronal damage. The number of apoptotic neurons and the apoptotic cell index decreased significantly in FA and NS treated group com-
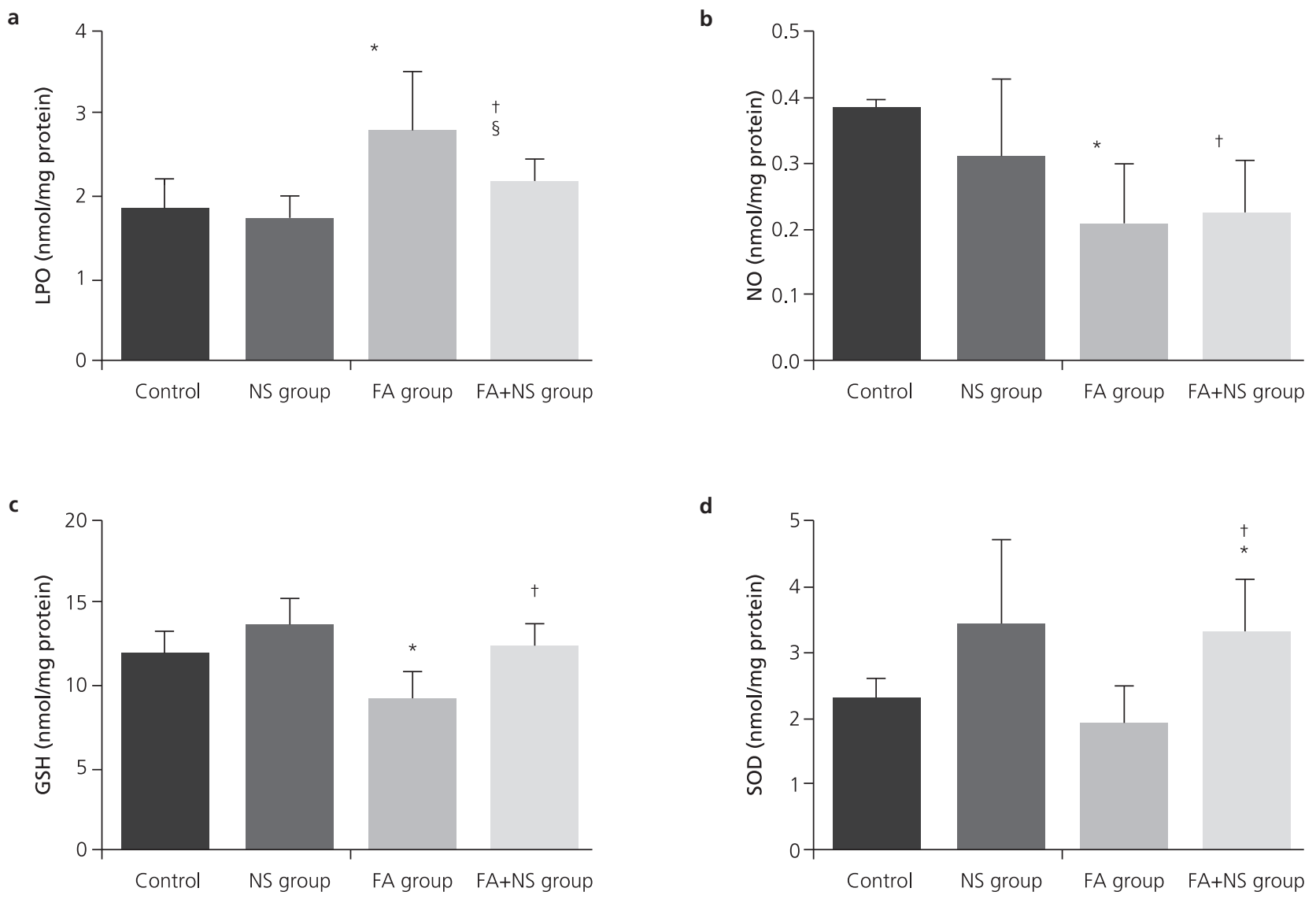

Figure 10. Brain tissue homogenate levels (mean \pm SE) of oxidative stress indices: (a) Lipid peroxides (LPO); (b) nitric oxide (NO); (c) glutathione (GSH); (d): superoxide dismutase (SOD) in different studied groups. ${ }^{*} p<0.001$ for comparison of all the studied groups versus controls. ${ }^{\dagger} p<0.001$ for comparison of FA-treated group versus FA+NS treated group, $\S p<0.05$ for comparison of all the studied groups versus controls. 
pared to FA-treated rats. The intensity of neurodegenerative changes was less than that in the FA-treated group. The number of darkly stained nuclei and distorted nerve cells reduced markedly with NS treatment. The severity of degenerative changes in the cytoplasm of the cells in NS and FA-treated group was less than that in the FAtreated group. This is in agreement with the results of Kanter $^{[33]}$ who reported protective effects of NS oil extract on FA-induced neuronal injury.

In our study, there was significant decrease in the levels of LPO in the brain tissue homogenate of FA and NS treated rats compared to FA-treated rats. Moreover, the level of NO increased significantly in the frontal lobe of the NS and FA-treated group compared to FA-treated rats. This is in agreement with the study of Ismail et al. ${ }^{[57]}$ who reported that thymoquinone had an inhibitory effect on lipid peroxidation and markedly improved plasma antioxidant status by inhibiting formation of hydroxyl radicals.

In the present study, the levels of GSH were significantly increased in NS and FA-treated group. In agreement with these results, Janero ${ }^{[58]}$ and Sheikh and Mohamadin ${ }^{[59]}$ showed that administration of NS restored the activities of non-enzymatic (GSH and vitamin C) and the enzymatic (SOD, CAT, GPx, and glutathione-S-transferase GST) antioxidants as well as reducing the level of malondialdehyde - the final decomposition product of membranes lipid peroxidation - to normal levels in the rat brain.

SOD is a metalloprotein that accomplishes its antioxidant functions by enzymatically detoxifying the superoxide anion. ${ }^{[57]}$ The present study showed that SOD significantly increased in FA and NS treated group compared to FA-treated group. These results are in agreement with the findings of Sheikh and Mohamadin ${ }^{[59]}$ and Nagi and Mansour ${ }^{[60]}$ who reported a potent superoxide radical scavenging activity of thymoquinone which is as effective as SOD against superoxides.

\section{Conclusion}

FA is associated with alterations in several indicators of oxidative stress changes in the frontal cortex of the rat. Administration of NS, an antioxidant and chelator, in FAtreated rats prevented these oxidative damages partially. The findings of the present study suggest that NS protects brain cells against oxidative stress caused by FA. Further investigations are needed for better understanding of the underlying mechanisms on the beneficial effect of NS, the active ingredient of NS causing this effect, as well as its optimum treatment dose and duration in the clinical management of FA-induced neuronal injury.

\section{Acknowledgments}

This study was supported by a grant (number SR-1450) from The Deanship of Scientific Research, Qassim University, Saudi Arabia. The authors wish the histology and biochemistry laboratory technicians for their assistance.

\section{References}

1. Cheng G, Shi Y, Sturla SJ, Jalas JR, McIntee EJ, Villalta PW, Wang M, Hecht SS. Reactions of formaldehyde plus acetaldehyde with deoxyguanosine and DNA: formation of cyclic deoxyguanosine adducts and formaldehyde cross-links. Chem Res Toxicol 2003;16:145-52.

2. Metz B, Kersten GF, Hoogerhout P, Brugghe HF, Timmermans HA, de Jong A, Meiring H, ten Hove J, Hennink WE, Crommelin DJ, Jiskoot W. Identification of formaldehyde-induced modifications in proteins: reactions with model peptides. J Biol Chem 2004;279:6235-43.

3. Chohen BL, Pangnillo MK, Musikant BL, Deutsch AS. Formaldehyde evaluation from endoplasmic materials. Oral Health 1998; 88:37-9.

4. Sarnak MJ, Long J, King AJ. Intravascular formaldehyde instillation and renal complication. Clin Nephrol 1999;51:122-5.

5. Conaway CC, Whysner J, Verna LK, Williams GM. Formaldehyde mechanistic data and risk assessement: endogenous protection from DNA adduct formation. Pharmacol Ther 1996;71:29-55.

6. Trezl L, Hullan L, Szavas T, Csiba A, Szende B. Determination of endogenous formaldehyde in plants (fruits) bound to L-arginine and its relation to the folate cycle, photosynthesis and apoptosis. Acta Biol Hung 1998;49:253-63.

7. Feron, VJ, Till HP, de Vrijer F, Woutersen RA, Cassee FR, van Bladeren PJ. Aldehyde: occurrence, carcinogenic potential, mechanism of action and risk assessment. Mutal Res 1991;259:363-85.

8. Simith AE. Formaldehyde. Occup Med 1992;42:83-8.

9. Ozen OA, Songur A, Sarsilmaz M, Yaman M, Kus I. Zinc, copper and iron concentrations in cerebral cortex of male rats exposed to formaldehyde inhalation. J Trace Elem Med Biol 2003;17:207-9.

10. Songur A, Akpolat N, Kus I, Ozen OA, Zararsiz I, Sarsilmaz M. The effects of the inhaled formaldehyde during the early postnatal period in the hippocampus of rats: a morphological and immunohistochemical study. Neurosci Res Commun 2003;33:168-78.

11. Trezl L, Tyihak E, Lotlikar PD. Non-enzymatic protein methylation and its biological significance in protein methylation. In: Paik WK, Kim S, editors. Protein methylation. Boca Raton (FL): CRC Press; 1990.

12. Solomons K and Cochrane JW. Formaldehyde toxicity. Part II. Review of acute and chronic effects on health. S Afr Med J 1984; 66:103-6.

13. Kilburn KH. Neurobehavioural impairment and seizures from formaldehyde. Arch Environ Health 1994;49:37-44.

14. Sorg BA, Hochstatter T. Behavioral sensitization after repeated formaldehyde exposure in rats. Toxicol Ind Health 1999;15:346-55.

15. Pitten FA, Kramer A, Herrmann K, Bremer J, Koch S. Formaldehyde neurotoxicity in animal experiments. Pathol Res Pract 2000;196:193-8.

16. Lu Z, Li CM, Qiao Y, Yan Y, Yang X. Effect of inhaled formaldehyde on learning and memory of mice. Indoor Air 2008;18:77-83. 
17. Stroup NE, Blair A, Erickson GE. Brain cancer and other causes of deaths in anatomists. J Natl Cancer Inst 1986;77:1217-24.

18. Reiter RL. Oxidative processes and antioxidative defense mechanisms in the aging brain. FASEB J 1995;9:526-33.

19. Patil AJ, Bhagwat VR, Patil JA, Dongre NN, Ambekar JG, Jailkhani R, Das KK. Effect of formaldehyde exposure on the activity of superoxide dismutase and catalase in battery manufacturing workers (BMW) of western Maharashtra (India) with reference to heme biosynthesis. Int J Environ Res Public Health 2006;3:329-37.

20. Halliwell B. Antioxidant and human disease: a general introduction. Nutrition 1997;55:544-52.

21. Kadiiska MB, Mason RP. Acute methanol intoxication generates free radicals in rats: an ESR spin trapping investigation. Free Radic Boil Med 2000;28:1106-14.

22. Halliwell B, Gutteridge JMC. Free radicals in biology and medicine. Oxford: Clarendon Press; 1989;186-87.

23. El-Tahir KE, Ashour MM, Al-Harbi MM. The respiratory effects of the volatile oil of the black seed (Nigella sativa) in guinea-pigs: elucidation of the mechanism(s) of action. Gen Pharmacol 1993; 24:1115-22.

24. Ghosheh OA, Houdi AA, Crooks PA. High performance liquid chromatographic analysis of the pharmacologically active quinones and related compounds in the oil of the black seed (Nigella sativa L.). J Pharm Biomed Anal 1999;19:757-62.

25. Hosseinzadeh H, Parvardeh S, Asl MN, Sadeghnia HR, Ziaee T. Effect of thymoquinone and Nigella sativa seeds oil on lipid peroxidation level during global cerebral ischemia-reperfusion injury in rat hippocampus. Phytomedicine 2007;14:621-7.

26. Padhye S, Banerjee S, Ahmad A, Mohammad R, Sarkar FH. From here to eternity-the secret of Pharaohs: Therapeutic potential of black cumin seeds and beyond. Cancer Ther 2008;6:495-510.

27. Hanafy MSM, Hatem ME. Studies on the antimicrobial activity of Nigella sativa seed (black cumin). J Ethnopharmacol 1991;34:275-78.

28. Zaoui A, Cherrah Y, Lacaille-Dubois MA, Settaf A, Amarouch H, Hassar M. Diuretic and hypotensive effects of Nigella sativa in the spontaneously hypertensive rats. Therapie 2000;55:379-82.

29. Kanter M, Coskun O, Budancamanak M. Hepato-protective effects of Nigella sativa L and Urtica diodica L on the lipid peroxidation, antioxidant enzyme systems and liver enzymes in carbon tetrachloride-treated rats. World J Gastroenterol 2005;11:6684-8.

30. Kanter M, Coskun O, Uysal H. The antioxidative and antihistaminic effects of Nigella sativa and its major constituents, thymoquinone on ethanol-induced gastric mucosal damage. Arch Toxicol 2006;80:217-24.

31. El-Kadi A, Kandil O. The black seed (Nigella sativa) and immunity: its effect on human T cell. Subset Fed Proc 1987;46:1222.

32. Uçmaklı E,Armutcu F, Öztürk A. The effects of formaldehyde intoxication on the inducible nitric oxide synthase expression and nitric oxide level in the liver tissue of rats. Turk J Med Sci 2013;43:52-6.

33. Kanter M. Protective effects of Nigella sativa on formaldehydeinduced neuronal injury in frontal cortex. Tip Araştırmaları Dergisi 2010;8:1-8.

34. Wang T, Zhao L, Guo Y, Zhang M, Pei H. Picroside II Inhibits neuronal apoptosis and improves the morphology and structure of brain tissue following cerebral ischemic injury in rats. PLoS ONE 2015;10:e0124099.
35. Thayer WS. Serum lipid peroxides in rats treated chronically with adriamycin. Biochem Pharmacol 1984;33:2259-63.

36. Van Bezooijen RL, Que I, Ederveen AG, Kloosterboer HJ, Papapoulos SE, Lowik CW. Plasma nitrate+nitrite levels are regulated by ovarian steroids but do not correlate with trabecular bone mineral density in rats. J Endocrinol 1998;159:27-34.

37. Misra HP, Fridouich I. The role of superoxide anion in the autooxidation of epinephrine and a simple assay for superoxide dismutase. J Biol Chem 1972; 274:3170-75.

38. Dutta P, Seirafi J, Halpin D, Pinto J, Rivlin R. Acute ethanol exposure alters hepatic glutathione metabolism in riboflavin deficiency. Alcohol 1995;12:43-7.

39. Salonen H, Pasanen AL, Lappalainen S. Volatile organic compounds and formaldehyde as explaining factors for sensory irritation in office enviroments. J Occup Environ Hyg 2009;6:239-47.

40. Zhang Y, Liu X, McHale C, Li R, Zhang L. Bone marrow injury induced via oxidative stress in mice by inhalation exposure to formaldehyde. PLoS ONE 2013;8:e74974.

41. Usanmaz SE, Akarsu ES, Vural N. Neurotoxic effect of acute and sub-acute formaldehyde exposures in mice. Environ Toxicol Pharmacol 2002;11:93-100.

42. Datta NJ, Namasivayam A. In vitro effect of methanol on folatedeficient rat hepatocyte. Drug Alcohol Depend 2003;71:87-91.

43. Farooqui MY, Upreti RK, Ahmed AE, Ansari GA. Influence of intraperitoneally administered formaldehyde on bile production and tissue glutathione levels in rats. Res Commun Chem Pathol Pharmacol 1986;53:233-6.

44. Tang XQ, Zhuang YY, Zhang P, Fang HR, Zhou CF, Gu HF, Zhang $\mathrm{H}$, Wang CY. Formaldehyde impairs learning and memory involving the disturbance of hydrogen sulfide generation in the hippocampus of rats. J Mol Neurosci 2013;49:140-9.

45. Daniel S, Limson JL, Amichand D, Watkins GM, Daya S. Through metal binding, curcumin protects against lead and cadmium- induced lipid peroxidation in rat brain homogenates and against lead-induced tissue damage in rat brain. J Inorg Biochem 2004;98:266-75.

46. Bennet C, Bettaiya R, Rajanna S, Baker L, Yallapragada PR, Brice JJ, White SL, Bokara KK. Region specific increase in the antioxidant enzymes and lipid peroxidation products in the brain of rats exposed to lead. Free Radic Res 2007;41:267-73.

47. Peluffo G, Calcerrada P, Piacenza L, Pizzano N, Radi R. Superoxide-mediated inactivation of nitric oxide and peroxynitrite formation by tobacco smoke in vascular endothelium: studies in cultured cells and smokers. Am J Physiol 2009;296:1781-92.

48. Kurata M, Suzuki M, Agar NS. Antioxidant systems and erythrocyte life-span in mammals. Comp Biochem Physiol B 1993;106:477-87.

49. Zararsiz I, Sonmez MF. Effects of omega-3 essential fatty acids against formaldehyde induced nephropathy in rats. Toxicol Ind Health 2006; 22:223-9.

50. Stohs SJ, Bagchi D. Oxidative mechanisms in the toxicity of metal ions. Free Radic Biol Med 1995;18:321-36.

51. Ding Y, Gonick HC, Vaziri ND. Lead promotes hydroxyl radical generation and lipid peroxidation in cultured aortic endothelial cells. Am J Hypertens 2000;13:552-55.

52. Saxena G, Flora SJS. Lead induced oxidative stress and hematological alterations and their response to combined administration of calcium disodium EDTA with a thiolchelator in rats. J Biochem Mol Toxicol 2004;18:221-33. 
53. Badary OA, Taha RA, Gamal A, El-Din M, Abdel-Wahab MH. Thymoquinone is a potent superoxide anion scavenger. Drug Chem Toxicol 2003; 26:87-98.

54. Nagi MN, Alam K, Badary OA, Al-Shabanah OA, Al- Sawaf HA, Al-Bekairi AM. Thymoquinone protects against carbon tetrachloride hepatotoxicity in mice via an antioxidant mechanism. Biochem Mol Biol Int 1999;47:153-9.

55. Kruk I, Michalska T, Lichszteld K, Kladna A, Aboul- Enein HY. The effect of thymol and its derivatives on reactions reactive oxygen species. Chemosphere 2000; 41:1059-64.

56. Al-Omar FA, Nagi MN, Abdulgadir MM, Al-Joni KS, Al-Majed AA. Immediate and delayed treatments with curcumin prevent forebrain ischemia-induced neuronal damage and oxidative insult in the rat hippocampus. Neurochem Res 2006; 31:611-9.
57. Ismail M, Al-Naqeep G, Chan KW. Nigella sativa thymoquinonerich fraction greatly improves plasma antioxidant capacity and expression of antioxidant genes in hypercholesterolemicrats. Free Radic Biol Med 2010;48:664-72.

58. Janero DR. Malondialdehyde and thiobarbituric acid-reactivity as diagnostic indexes of lipid-peroxidation and peroxidative tissueinjury free radical biology and medicine. Free Radic Biol Med 1990;9:515-40.

59. Sheikh BY, Mohamadin AM. Thymoquinone a potential therapy for cerebral oxidative stress. Asian J Nat Appl Sci 2012;1:76-92.

60. Nagi MN, Mansour MA. Protective effect of thymoquinone against doxorubicin-induced cardiotoxicity in rats: a possible mechanism of protection. Pharmacol Res 2000;41:283-89.

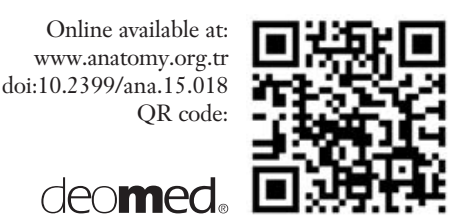

\author{
Correspondence to: Tarek Mohamed Essa, MD \\ Department of Anatomy, Faculty of Medicine, \\ Qassim University, Qassim, Saudi Arabia \\ Phone: +201115 509509 \\ e-mail: tarek_essa612000@yahoo.com \\ Conflict of interest statement: No conflicts declared.
}

This is an open access article distributed under the terms of the Creative Commons Attribution-NonCommercial-NoDerivs 3.0 Unported (CC BY-NCND3.0) Licence (http://creativecommons.org/licenses/by-nc-nd/3.0/) which permits unrestricted noncommercial use, distribution, and reproduction in any medium, provided the original work is properly cited. Please cite this article as: Muhammad AE, Essa TM, Ata HS. Nigella sativa protects against formaldehyde-induced neurotoxicity in the rat frontal cortex. Anatomy 2015;9(3):117-127. 